\title{
Impactos do Fundeb sobre a qualidade do ensino básico público: uma análise para os municípios do estado do Rio de Janeiro*
}

\author{
Bruno Cesar Campos** \\ Breno de Paula Andrade Cruz***
}

Sumário: 1. Introdução; 2. Método de estimação log-lin; 3. O desenvolvimento educacional nos municípios do Rio de Janeiro e as receitas do Fundeb; 4. O Fundeb e a infraestrutura escolar no estado do Rio de Janeiro; 5. Considerações finais.

Summary: 1. Introduction; 2. Log-lin estimation method; 3. Educational development in Rio de Janeiro municipalities and Fundeb's revenues; 4. Fudeb and school infrastructure in the state of Rio de Janeiro; 5. Final remarks.

Palavras-chave: educação básica; Fundeb; rede pública de ensino.

KeY wORDs: basic education; Fundeb; public education.

Regulamentado em 2006, o Fundo de Manutenção e Desenvolvimento da Educação Básica e de Valorização do Magistério (Fundeb) representa um avanço no financiamento da educação pública brasileira. Ao vincular uma parcela considerável de receitas à manutenção de todas as modalidades do ensino básico, o fundo pode contribuir para a redução do analfabetismo, universalização do ensino básico (da educação infantil até o ensino médio), entre outros benefícios. Mas a política de vinculação dos recursos, isoladamente, pode não ser suficiente para a mitigação de todos os problemas apresentados pela educação pública brasileira. Este artigo mostra que parece não existir uma correlação estatisticamente significativa entre o

\footnotetext{
* Artigo recebido em mar. e aceito em out. 2008. A primeira versão deste artigo foi apresentada no XXXI Enanpad e recebeu o prêmio de melhor artigo da área APS-B (Gestão e Políticas Públicas).

$*$ Mestre em economia pela Universidade Federal Fluminense (UFF), economista da Petrobras. Endereço: Av. República do Chile, 65, sala 1.201 — CEP 20031-912, Rio de Janeiro, RJ, Brasil. E-mail: bcampos@petrobras.com.br.

*** Mestre em administração pública pela Escola Brasileira de Administração Pública e de Empresas da Fundação Getulio Vargas (Ebape/FGV). Professor de graduação da Fundação Getulio Vargas. Endereço: Rua Barão de Itambi, 60, 9o andar — CEP 22231-000, Rio de Janeiro, RJ, Brasil. E-mail: breno.cruz@fgv.br.
} 
volume de recursos disponíveis para o investimento em educação pública e o grau de desenvolvimento da mesma. A partir de um exercício estatístico desenvolvido para os municípios do estado do Rio de Janeiro, mostrou-se que o Fundeb não garante um maior aporte de recursos para os municípios mais atrasados do ponto de vista educacional. Ademais, argumenta-se que o direcionamento de recursos é condição necessária, porém não suficiente, para se melhorar a educação pública brasileira. A boa aplicação das receitas do fundo é fundamental para o êxito do mesmo.

Impacts of the Fundeb on the quality of public basic education: an analysis for the municipalities of the state of Rio de Janeiro

Regulated in 2006, the Fund for Basic Education and for Enhancing the Value of the Teaching Profession (Fundeb) represents a step further in financing Brazilian public education. By securing a considerable part of the revenues for basic education in all its modalities, the fund can contribute to the reduction of illiteracy and the universality of basic education (from elementary to middle school), among other benefits. However, the policy of securing financing by itself is not enough to mitigate all Brazilian public education issues. This article shows that there does not seem to exist a statistically significant co-relation between the amount of resources available for investment in public education and its degree of development. From a statistical exercise developed for the municipalities of the state of Rio de Janeiro, one can see that Fundeb does not ensure a larger financial allocation for the most underserviced municipalities from the education standpoint. Furthermore, although the allocation of resources is necessary, it is not enough to improve the Brazilian public education. The good use of resources from the fund is the key to success.

\section{Introdução}

Não se questionam os inúmeros avanços nos indicadores educacionais brasileiros nos últimos anos. Embora ainda ostente taxas de analfabetismo altas, sobretudo se comparado com países desenvolvidos, o Brasil vem conseguindo reduções graduais na proporção de analfabetos. De acordo com o Instituto Brasileiro de Geografia e Estatística (IBGE), entre os censos de 1991 e 2000, o percentual de analfabetos na população brasileira com idade superior a 25 anos caiu de $22,8 \%$ para $16 \%$ (IBGE, 2007).

O ensino médio tem registrado importantes avanços. As taxas brutas de matrícula $^{1}$ da rede pública da modalidade evoluíram de $61 \%$ para $67,9 \%$ no

\footnotetext{
${ }^{1}$ A taxa bruta de matrícula é calculada dividindo-se o total de alunos da modalidade de ensino pela população que se encontra na faixa de idade considerada adequada para cursar a mesma. No caso do ensino médio, por exemplo, divide-se o total de alunos pela população com idade entre 15 e 17 anos.
} 
curto intervalo de 1999 a 2005 (Inep, 2007). Isso equivale a dizer que o número de alunos da rede pública brasileira já beira $70 \%$ da população com idade entre 15 e 17 anos. Entretanto, se considerarmos que a taxa bruta de matrículas engloba também os alunos repetentes e em idade defasada, podemos argumentar que um considerável caminho ainda precisa ser percorrido rumo à universalização desse nível de ensino. A Pesquisa Nacional por Amostra de Domicílios (Pnad), desenvolvida pelo IBGE, acusa que, em 2005, aproximadamente $36 \%$ dos jovens brasileiros de 15 a 17 anos estavam matriculados no ensino médio. Tal indicador, conhecido como taxa líquida de matrículas, aponta que o número de abandonos e de jovens frequentando a escola em idade defasada ainda é expressivo.

As consecutivas melhoras nos indicadores do ensino médio possibilitam aperfeiçoamentos também nos resultados da educação superior. O intervalo entre os censos de 1991 e 2000 aponta progressos que, no entanto, ainda podem ser muito melhores. A proporção de indivíduos com idade entre 18 e 29 anos matriculados em cursos de formação superior em todo o país passou de $3,5 \%$ para $5,5 \%$. A proporção da população de 25 anos ou mais com diploma de graduação também aumentou no mesmo período: passou de 5,9\% em 1991 para $7,4 \%$ em 2000.

Recentemente, a principal conquista do país no campo educacional está relacionada à universalização do ensino fundamental. Atualmente, é marginal a proporção de crianças na faixa etária de sete a 14 anos que não frequentam a escola. O Fundo de Manutenção e Desenvolvimento do Ensino Fundamental e de Valorização do Magistério (Fundef), associado a programas como o Bolsa Escola, o Bolsa Família e o de Erradicação do Trabalho Infantil (Peti) tiveram papel decisivo nessa conquista.

Paralelo ao esforço de ampliação do acesso à escola, emerge a necessidade de se investir na qualidade da educação, especialmente a educação pública básica. É imprescindível a necessidade de se aumentar a carga horária diária dos alunos, investindo-se na qualidade do material didático e na formação do professorado.

No intuito de estender os progressos alcançados no ensino fundamental para todas as modalidades do ensino básico aprovou-se, em 2006, o Fundeb - Fundo de Manutenção e Desenvolvimento da Educação Básica e de Valorização dos Profissionais da Educação. O funcionamento do Fundeb preserva essencialmente as mesmas características do Fundef. Parcelas fixas da arrecadação de estados e municípios são incorporadas ao fundo, que redistribui esses recursos de acordo com a proporção de matrículas nas redes estaduais 
e municipais de ensino público. As modalidades de ensino cobertas incluem a educação infantil (creche e pré-escola), o ensino fundamental, o ensino médio e a educação de jovens e adultos (EJA).

As receitas estaduais vinculadas ao Fundeb incluem o Fundo de Participação dos Estados (FPE) e os recursos arrecadados com o imposto sobre a circulação de mercadorias e serviços (ICMS), o imposto sobre a propriedade de veículos automotores (IPVA), a quota do imposto sobre produtos industrializados (IPI-Exp) e o imposto sobre transmissão causa mortis e doação (ITCD). Já as receitas municipais vinculadas são: fundo de participação dos municípios (FPM), quota do ICMS, quota do IPVA, quota do imposto territorial rural (ITR) e quota do IPI-Exp.

Este artigo traça o potencial do Fundeb como instrumento de aperfeiçoamento das condições de oferta da educação pública básica nos municípios do estado do Rio de Janeiro. Detentora da terceira maior rede pública de ensino básico do país, essa unidade federativa atendia 3,2 milhões de alunos de ensino básico em sua rede no ano de 2005 (Inep, 2007). A exemplo da realidade assistida em praticamente todo o país, o estado do Rio de Janeiro apresenta significativas disparidades intraestaduais. Seus 92 municípios detêm potenciais de arrecadação bastante distintos, o que interfere diretamente no volume de recursos aportados para o fundo.

$\mathrm{O}$ artigo mostra que, apesar dos indiscutíveis méritos, o Fundeb não garante que os municípios com os piores indicadores educacionais poderão contar com um maior aporte de recursos. Exercícios estatísticos apontam que as melhores infraestruturas educacionais não necessariamente estão associadas aos municípios com maior disponibilidade de recursos para serem investidos em educação via Fundeb. Tal panorama aponta para a importância de medidas que garantam a boa gestão dos recursos disponibilizados para a educação, sugerindo que os municípios mais ricos nem sempre apresentam as melhores condições de infraestrutura escolar em suas redes públicas.

Além da introdução e das considerações finais, o artigo traz mais três seções. A segunda apresenta um resumo da metodologia utilizada para a estimação das receitas do Fundeb. A terceira confronta as estimativas elaboradas para cada município fluminense com o desenvolvimento educacional dos mesmos. Na quarta seção são desenvolvidos exercícios estatísticos que apontam para a inexistência de correlações significativas entre os recursos aportados pelo Fundeb e o grau de desenvolvimento das características estruturais dos estabelecimentos de ensino de cada município. 


\section{Método de estimação log-lin}

De acordo com a Emenda Constitucional no 53/2006 (Brasil, 2007a), o Fundeb levará três anos para ser efetivamente implementado. Em vista disso, este artigo se preocupou em produzir estimativas para os próximos três anos, julgando que, a partir do terceiro ano, as perspectivas para o financiamento da educação pública brasileira estariam mais próximas de um cenário de estabilidade.

Estimativas das receitas disponíveis para a composição do fundo nos próximos anos foram produzidas com base em séries históricas fornecidas pela Secretaria do Tesouro Nacional (Brasil, 2007b) e pelo Tribunal de Contas do Estado do Rio de Janeiro. A partir das séries históricas, que cobrem o período compreendido entre 1998 e 2005, foram calculadas projeções econométricas.

Uma vez que elas se mostraram estatisticamente significativas, foi possível supor que, em condições normais, as receitas governamentais constituintes do Fundeb deverão evoluir de maneira comportada nos próximos anos. As taxas de crescimento tendenciais foram aplicadas para os próximos períodos, sendo razoável supor que, nos anos imediatamente subsequentes, as séries crescerão a taxas muito próximas das calculadas com base nos últimos anos.

Para o cálculo da evolução das receitas que compõem o Fundeb, as séries históricas de receitas foram submetidas ao tratamento econométrico de estimação log-lin (Greene, 2001:634-645). Em tal método, a taxa de crescimento em uma série histórica parte da fórmula básica de capitalização:

$$
Y_{t}=Y_{0}(1+r)^{t}
$$

onde $Y_{t}$ é a variável que se pretende estimar, $Y_{0}$ representa seu estágio inicial, $r$ representa a taxa de crescimento e $t$ representa o tempo.

Aplicando logaritmos a (1), temos:

$$
\ln Y_{t}=\ln Y_{0}+t \ln (1+r)
$$

Chamando $\ln Y_{0}$ de $\beta_{1}$, e $\ln (1+r)$ de $\beta_{2}$, podemos reescrever a expressão (2), associando-a a uma regressão:

$$
\ln Y_{t}=\beta_{1}+\beta_{2} t+u
$$

onde $u$ está relacionado ao erro estatístico. 
Sendo a variável dependente $\left(\ln Y_{t}\right)$ associada a um logaritmo e a variável explicativa $(t)$ uma variável linear (daí o nome $\log$-lin), $\beta_{2}$ pode ser interpretado da seguinte forma: variação relativa no regressando/variação absoluta no regressor.

Neste artigo foram estimadas regressões pelo método dos "mínimos quadrados ordinários", em que a variável dependente era constituída pelo logaritmo das variáveis analisadas, regredidas no tempo. ${ }^{2}$ Os coeficientes encontrados nas regressões expressavam a taxa instantânea de crescimento, isto é, a taxa em um ponto do tempo. Quando estatisticamente significativos, calculava-se o anti-log desses coeficientes de modo a possibilitar a obtenção da taxa de crescimento composta, que se aplica a um decurso de período.

Para que tal técnica fosse adotada, partiu-se da hipótese de que tanto as receitas relacionadas ao Fundeb quanto as matrículas no ensino fundamental compreendiam séries temporais estacionárias, ou seja, séries cuja média e variância não se alteram sistematicamente ao longo do tempo. Testes de raiz unitárias corroboraram a hipótese.

As taxas de crescimento encontradas só foram utilizadas se estatisticamente significativas com teste de raiz unitária também significativo. Caso contrário, lançou-se mão da taxa média geométrica de crescimento, de cálculo mais simples, porém mais adequada a séries muito erráticas.

\section{O desenvolvimento educacional nos municípios do Rio de Janeiro e as receitas do Fundeb}

Espera-se que o Fundeb funcione como instrumento de aperfeiçoamento das condições de acesso à educação básica no país, minorando as disparidades inter-regionais, sem descuidar, todavia, das questões intrarregionais. Os 92 municípios do estado do Rio de Janeiro apresentam diferentes condições de acesso à educação, e isso se reflete nos resultados do índice de desenvolvimento humano - educação (IDH-E). Tal índice é um indicador econômico derivado do trabalho do Prêmio Nobel de Economia Amartya Sen, que argumentou que as informações de renda podem não ser suficientes para retratar os estágios de desenvolvimento econômico de um país ou região (Sen, 2000).

\footnotetext{
${ }^{2}$ As regressões foram elaboradas a partir do pacote computacional Eviews.
} 
Para esse autor, muito além da renda, é necessário que os indivíduos gozem de outros direitos, que ele chamou de "liberdades". Essas liberdades incluem a garantia dos direitos básicos como saúde e educação, oportunidades de ascensão, proteção contra a violência e arbitrariedades, invulnerabilidade contra a fome e a pobreza extrema, entre outros fatores. Variáveis de renda, educação, saúde, mobilidade social, entre outras, foram usadas na tentativa de se mensurar o desenvolvimento humano numa ótica mais abrangente do que a restrita à renda.

O IDH-E é um índice que congrega diversos indicadores de educação, incluindo variáveis de alfabetização e acesso aos diferentes níveis educacionais - desde o ensino elementar até o superior (FJP, 2003). Quanto maior o índice (que pode chegar até um), melhores as condições de acesso à educação em determinada região.

A tabela 1 apresenta o IDH-E de cada município fluminense nos anos de 1991 e $2000 .^{3}$ Ela dividiu os municípios em três grupos: municípios que em 2000 apresentaram IDH-E inferior à média dos municípios com pelo menos um desvio padrão de diferença; municípios que em 2000 apresentaram IDH-E em torno da média dos municípios com até um desvio padrão de diferença; e municípios que em 2000 apresentaram IDH-E superior à média dos municípios com pelo menos um desvio padrão de diferença.

Dos 92 municípios fluminenses, 64 demonstram IDH-E 2000 relativamente próximos da média dos municípios (colunas intermediárias), refletindo razoável homogeneidade no estado. Outros 17 municípios apresentaram resultado bem abaixo da média (primeiras colunas), sendo eles os municípios onde as condições de acessibilidade à escola devem ser tratadas com maior atenção. A lista inclui os seguintes municípios: Bom Jardim, Cambuci, Cardoso Moreira, Duas Barras, Laje do Muriaé, Paty do Alferes, Rio Claro, Santa Maria Madalena, Sapucaia, Silva Jardim, Sumidouro, São Francisco de Itabapoana, São José de Ubá, São José do Vale do Rio Preto, São João da Barra, Trajano de Morais e Varre-Sai.

No outro extremo, 10 municípios se destacaram em relação aos seus congêneres, apresentando, em 2000, IDH-E superior à média dos municípios, com pelo menos um desvio padrão de diferença (últimas colunas).

\footnotetext{
${ }^{3} \mathrm{O}$ município de Mesquita foi excluído da análise por apresentar problemas de indisponibilidade nos dados.
} 


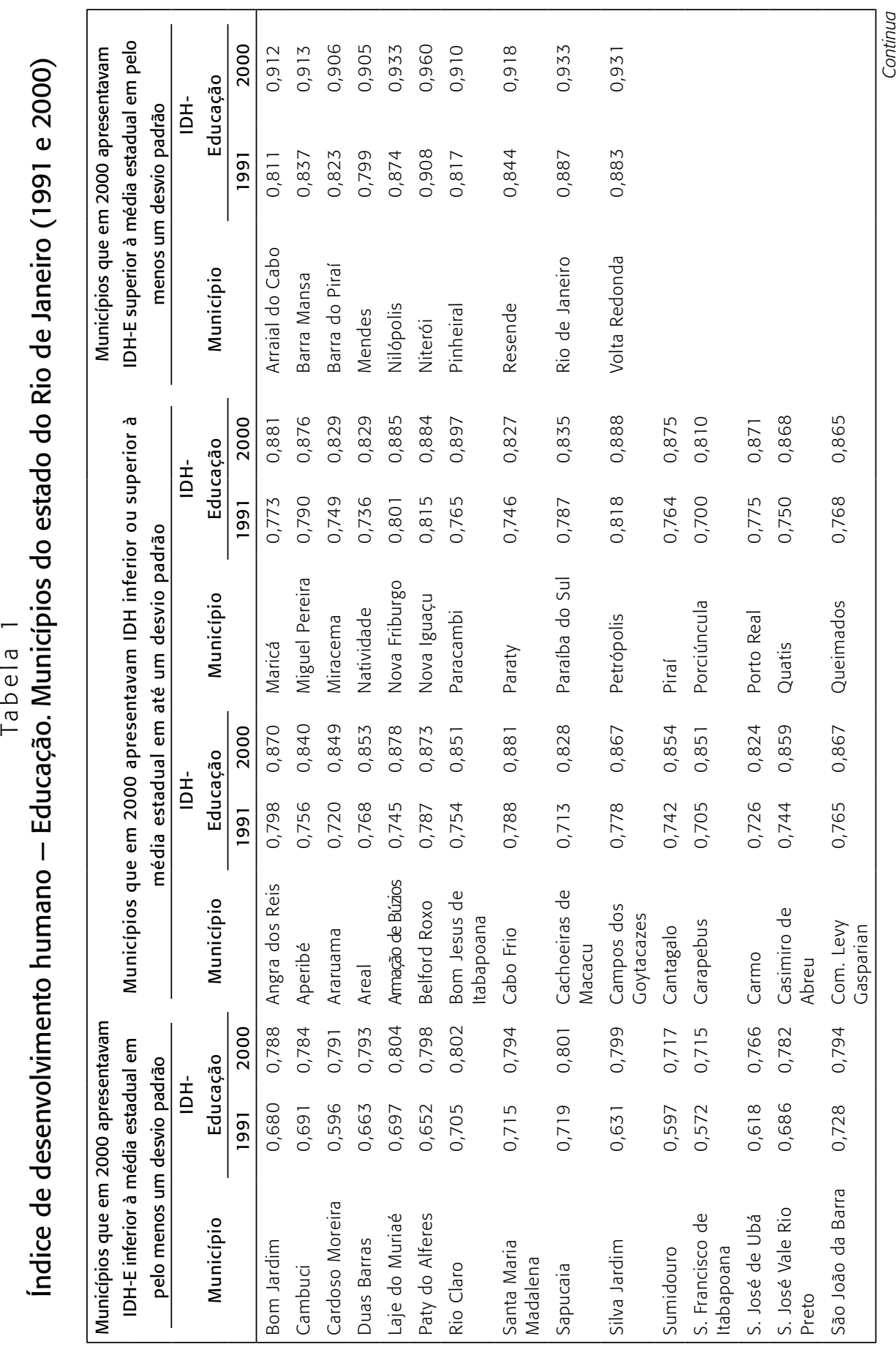




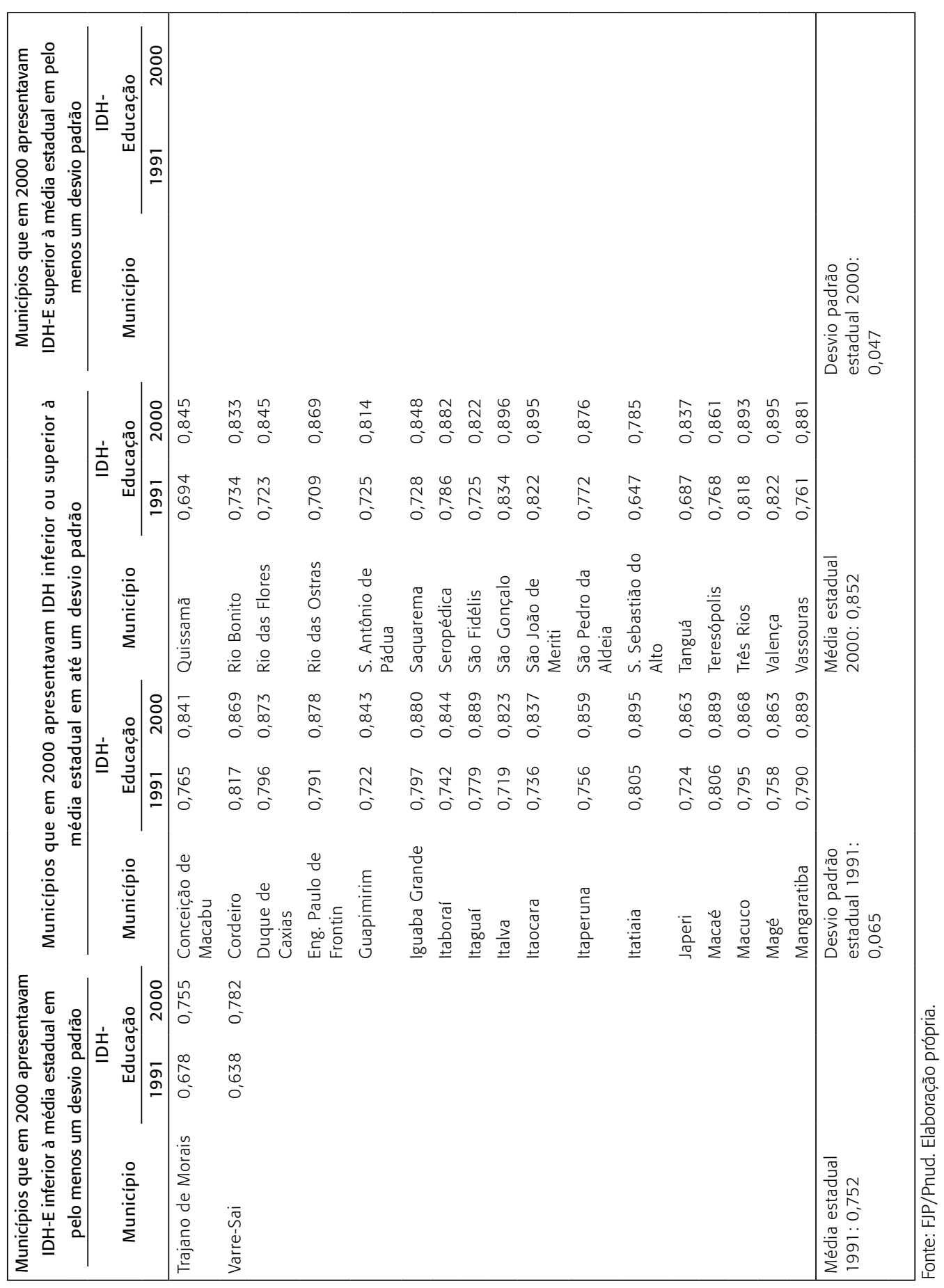


Essa lista incluiria os municípios do estado com melhores condições de acesso à educação em todos os níveis. A lista contempla: Arraial do Cabo, Barra Mansa, Barra do Piraí, Mendes, Nilópolis, Niterói, Pinheiral, Resende, Rio de Janeiro e Volta Redonda.

Contrapondo-se a esse indicador, a tabela 2 apresenta uma estimativa da magnitude do Fundeb em cada um dos municípios do estado do Rio de Janeiro. O intuito é verificar se os municípios com piores condições de acesso à educação tenderão a apresentar, também, baixos investimentos no ensino básico, ponderados pelo tamanho de suas economias. Tais estimativas foram construídas com base na metodologia descrita na seção 2 .

Como referência, foram usadas as estimativas de receitas para 2009, ano em que o Fundeb estará efetivamente implementado. ${ }^{4}$ As mesmas foram divididas pelo PIB de cada município. Tal informação foi obtida junto ao IBGE para o ano de 2003 (IBGE, 2007). Para se chegar à estimativa do PIB de 2009, foram utilizadas as taxas de crescimento do PIB brasileiro nos anos de 2004 e 2005 e também as taxas de crescimento estimadas para os próximos anos até 2009 (BCB, 2007). A exemplo da tabela 1, a tabela 2 divide os municípios fluminenses em três grupos: municípios que apresentam razão Fundeb/PIB inferior à média dos municípios fluminenses com pelo menos um desvio padrão de diferença; municípios que apresentam razão Fundeb/ PIB em torno da média dos municípios fluminenses com até um desvio padrão de diferença; e municípios que apresentam razão Fundeb/PIB superior à média dos municípios fluminenses com pelo menos um desvio padrão de diferença.

As diferenças observadas no dinamismo econômico dos municípios fluminenses interferem diretamente no potencial de arrecadação de cada um. O peso do Fundeb na economia dos mesmos também se mostra bastante distinto.

Foram 18 municípios que apresentaram uma razão Fundeb/PIB consideravelmente inferior à média de todas as municipalidades (primeiras colunas). Na maior parte dos casos, são municípios com alto dinamismo econômico, em

\footnotetext{
${ }^{4}$ Até 2009, o fundo deverá cobrir apenas parte das matrículas do ensino básico, vinculando uma parcela menor de recursos. Dessa forma, optou-se pela análise do ano de 2009 com o argumento de que apenas neste ano o Fundeb deverá estar efetivamente implementado.
} 
que a magnitude do Fundeb fica relativamente pequena. Esse é o caso, por exemplo, da capital e de municípios como Campos dos Goytacazes (receptor de royalties do petróleo), Porto Real (sede de uma montadora de veículos) ou Volta Redonda (sede de uma indústria siderúrgica).

Não é possível afirmar que, necessariamente, esses municípios invistam pouco em educação em termos absolutos. Em muitos casos, é de se esperar que a média de gastos por aluno desses municípios supere a média de municípios de outros grupos. Contudo, pode-se dizer que esses municípios são os que apresentam maiores condições de ampliarem os investimentos em educação.

Em posição oposta, para outros 11 municípios do estado, as receitas do Fundeb deverão exercer papel de peso (últimas colunas). Nesses municípios, a razão Fundeb/PIB é pelo menos um desvio padrão superior à razão Fundeb/ PIB média do estado. Em boa parte dos casos, são municípios com baixo dinamismo econômico, o que pode representar um empecilho para a ampliação dos investimentos em educação. Casos como os dos municípios de Cardoso Moreira, Laje do Muriaé, Santa Maria Madalena e Varre-Sai chamam a atenção. Além de apresentarem baixo IDH-E (tabela 1), a dimensão do Fundeb na economia desses municípios já é elevada (tabela 2), o que pode se refletir em dificuldades para que esses municípios invistam em educação básica pública além das dotações do fundo.

O instrumental analítico aqui proposto serve para reforçar o argumento de que esforços de aperfeiçoamento da qualidade da educação pública brasileira ainda precisam ser conciliados com esforços de ampliação do público atendido. Os municípios fluminenses se encontram em diferentes estágios de desenvolvimento da cobertura educacional e registram, ainda, diferentes dotações de recursos para construir uma educação pública adequada.

É fundamental garantir um ensino de qualidade, que subentende uma educação pública inclusiva, que agregue valores e conhecimento para todos os indivíduos de forma a proporcionar-lhes condições de inserção digna no mercado de trabalho, preparando-os também para a plena prática da cidadania. 


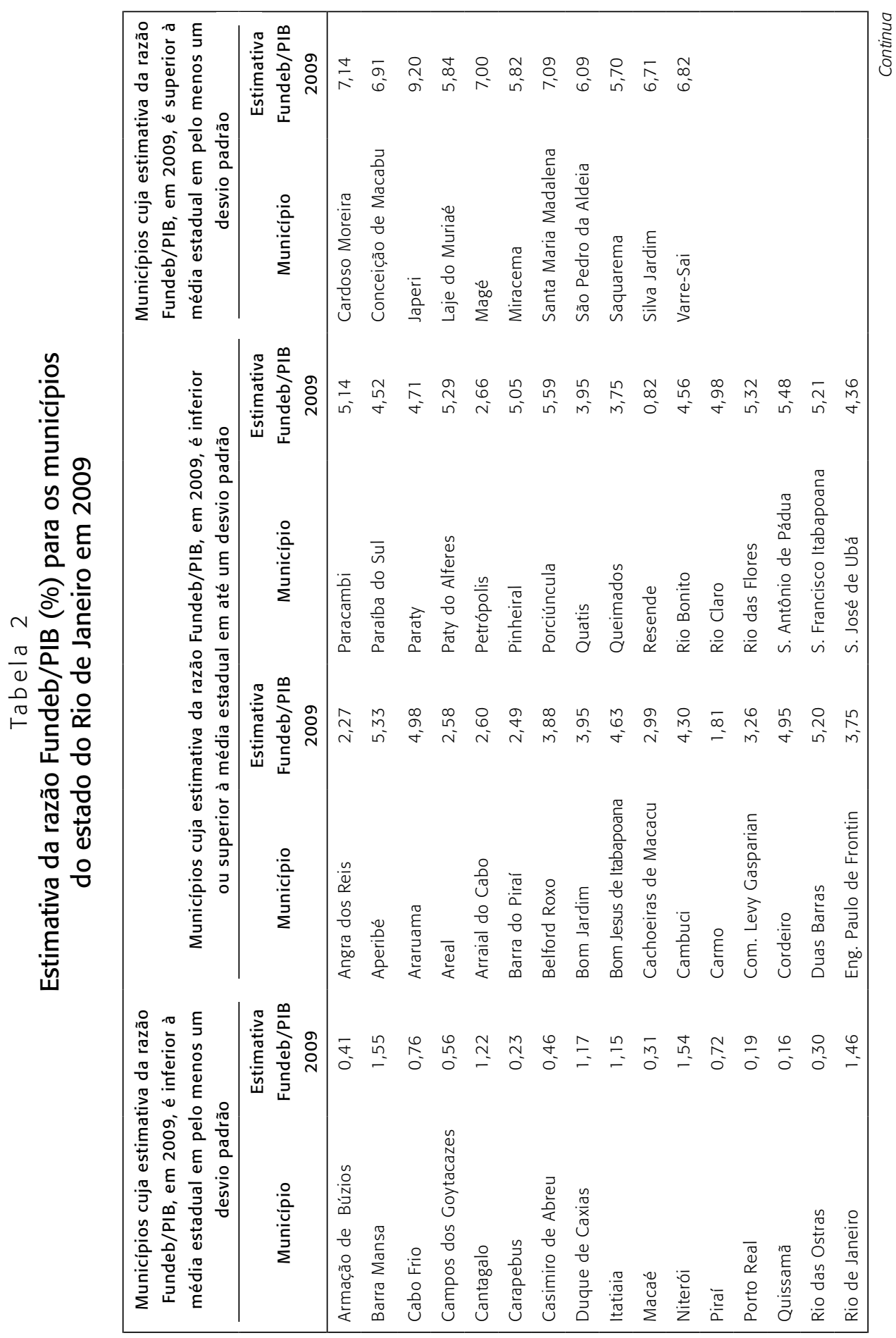




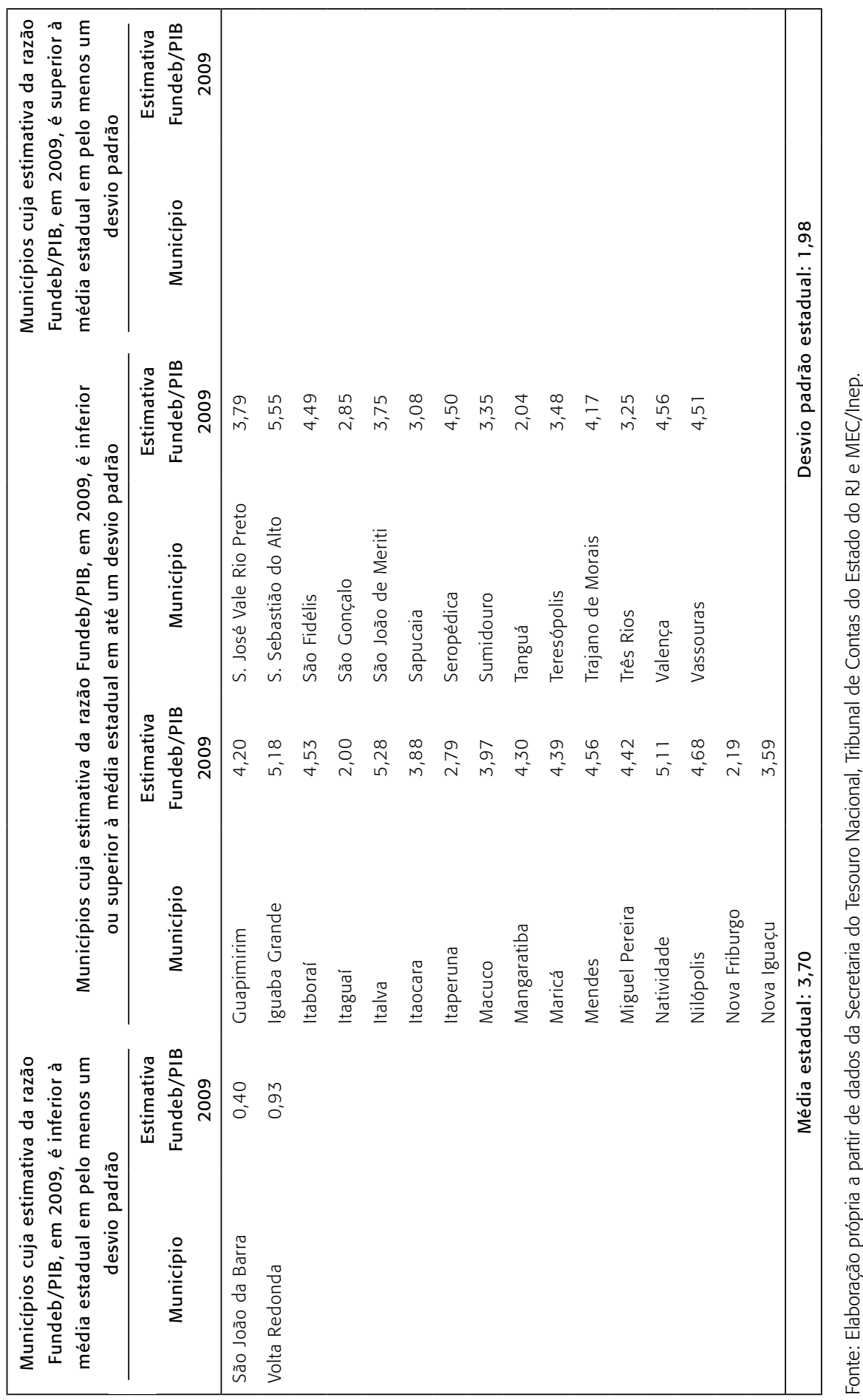

RAP - RIO DE JANEIRO 43(2):371-93, MAR./ABR. 2009 


\section{O Fundeb e a infraestrutura escolar no estado do Rio de Janeiro}

Uma escola de qualidade subentende o preenchimento de certos requisitos. Oferecer instalações confortáveis e adequadas aos alunos é o mínimo que se pode esperar de um estabelecimento de ensino. É possível argumentar, ainda, que a complexidade dos conhecimentos exigidos de um profissional moderno exige que ele seja capaz de apreender informações de formas variadas, o que torna ultrapassada a escola que garanta apenas a presença de um professor diante de um quadro-negro.

Muito além da sala de aula, espera-se que as escolas contemporâneas garantam aos alunos acesso a determinadas facilidades que contribuam para sua formação. A existência de bibliotecas, salas de informática com acesso à internet, quadras de esporte, entre outros fatores, além de estimular a frequência dos alunos, contribui para uma formação mais completa e eficaz. Não se pode negar que a existência dessas facilidades, sem uma adequada formação do corpo docente e a disponibilidade de um material didático de qualidade, pode apresentar resultados inócuos. Entretanto, é inegável que a existência desse tipo de infraestrutura tem a contribuir para a formação dos alunos.

Diferentemente de outras unidades federativas, o estado do Rio de Janeiro dispõe de escolas públicas de educação básica com condições mínimas de aprendizagem. De acordo com o Inep (2007), a quase totalidade dos alunos (percentuais superiores a 93\%) estuda em escolas dotadas de água tratada, energia elétrica, sanitário e rede de esgoto. De forma um tanto quanto surpreendente, não é difícil encontrar casos de unidades federativas (sobretudo nas regiões Norte e Nordeste do Brasil) que mantêm até $20 \%$ de seus alunos estudando em escolas públicas de ensino básico sem esse tipo de infraestrutura (Sobreira e Campos, 2006).

A partir da constatação de que o problema da infraestrutura básica das escolas públicas do Rio de Janeiro apresentava condições razoáveis, este artigo estudou o estágio de desenvolvimento da infraestrutura complementar das instituições de ensino, investigando em que medida o Fundeb tem potencial para aprimorá-la. Foram pesquisados os municípios que apresentavam a maior proporção de alunos de escolas públicas matriculados em escolas dotadas de infraestrutura complementar, checando se os municípios com pior desempenho tenderão a receber um volume proporcionalmente superior de recursos, de forma a conseguirem reverter o estágio de atraso. 
Desenvolveu-se para tanto um indicador formado pela proporção de alunos de escolas públicas de ensino fundamental e médio que estudaram (em 2005) em estabelecimentos com as seguintes facilidades: biblioteca; quadra de esportes; laboratório de ciências; microcomputador; laboratório de informática; e internet.

O exercício ficou restrito apenas a essas duas modalidades por serem as mais importantes do ensino básico. Ademais, o tipo de infraestrutura requerido por uma creche ou pré-escola de qualidade, por exemplo, pode se diferenciar do requerido por uma escola de ensino fundamental ou médio.

Os indicadores de cada município foram confrontados com a razão "recursos previstos para o Fundeb em 2009/PIB municipal", cuja metodologia de construção já foi descrita.

A correlação entre os dois indicadores foi investigada, e a expectativa era de que os municípios com as maiores dotações de recursos apresentariam também as melhores condições de infraestrutura escolar.

A primeira correlação apresentada trata do acesso a bibliotecas. A figura 1 faz o cruzamento das variáveis "razão Fundeb/PIB" (eixo horizontal) e "proporção de matrículas públicas em escolas de ensino fundamental e médio com biblioteca" (eixo vertical). Cada um dos pontos do gráfico representa um município fluminense. Ao contrário do que se poderia supor, não existe correlação positiva e estatisticamente significativa entre as duas variáveis. Além de não significativa, a correlação elaborada para o ensino fundamental foi negativa. A correlação para o ensino médio é positiva, e o fato de não se mostrar estatisticamente significativa pode estar associado ao argumento de que muitos municípios oferecem bibliotecas para todos os alunos de ensino médio público, independentemente da dotação de recursos.

A dispersão da nuvem de pontos sugere que o acesso a essa facilidade por parte dos alunos da rede pública de ensino médio é bem maior do que o acesso dos alunos da rede pública de ensino fundamental. Chama a atenção um resultado que, em grande medida, se repetirá nas correlações apresentadas na sequência: municípios com dotações de recursos similares demonstram desempenhos consideravelmente diferentes. Assim, pode-se argumentar que não há garantia de que o Fundeb destinará maior volume de recursos para municípios de pior desempenho nos indicadores educacionais, contribuindo, assim, para a reversão das disparidades intrarregionais. 


\section{Figura 1}

Correlações entre a razão Fundeb/PIB 2009 e a proporção de alunos dos ensinos fundamental/médio matriculados em escolas com biblioteca (municípios do estado do Rio de Janeiro)

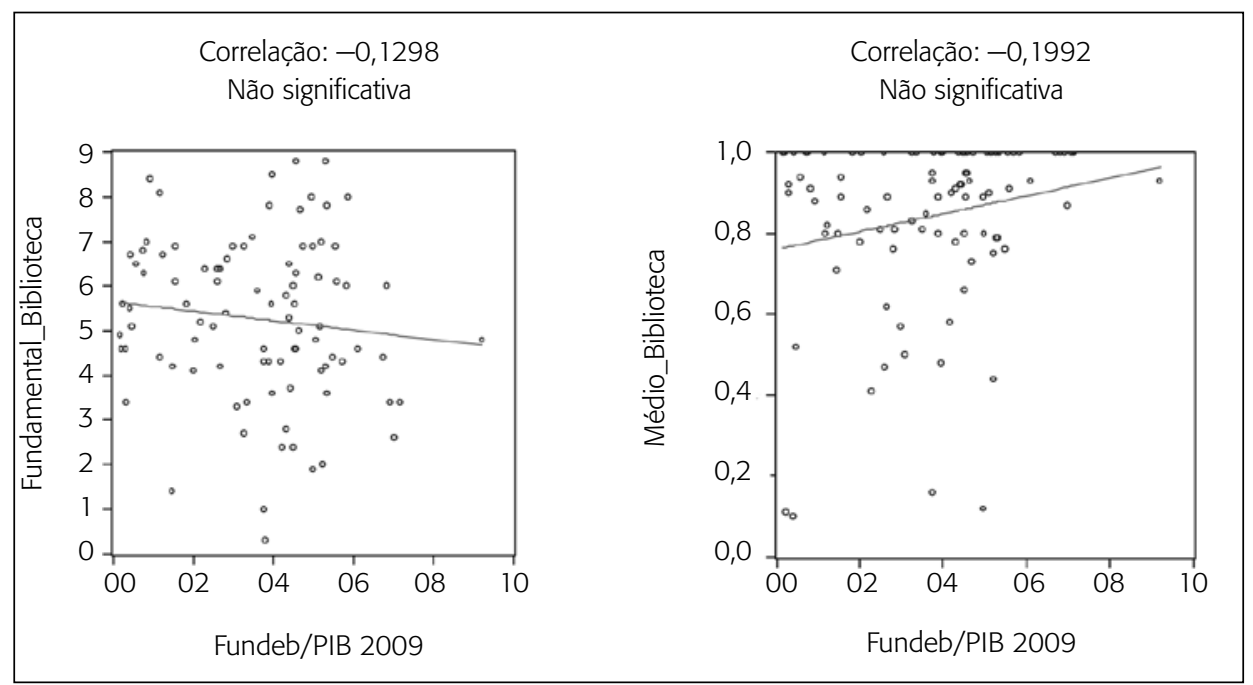

Fonte: Elaboração própria a partir de dados da Secretaria do Tesouro Nacional, Tribunal de Contas do Estado do Rio de Janeiro e MEC/Inep.

A figura 2 repete o exercício para a disponibilidade de quadras de esporte. O resultado é similar ao encontrado para o caso do acesso a bibliotecas. As escolas públicas de ensino médio dos municípios fluminenses, independentemente do volume proporcional de recursos esperados com o Fundeb, já oferecem quadras de esportes para boa parte dos alunos. Talvez por esse motivo, a relação positiva entre a "razão Fundeb/PIB 2009" versus a "proporção de matrículas de ensino médio público em escolas com quadra de esportes" $(0,0121)$ tenha sido não significativa.

Já para o ensino fundamental, a não significância da correlação deve estar relacionada ao fato de que municípios com dotações de recursos parecidas oferecem essa facilidade de formas muito distintas. A correlação se mostrou negativa $(-0,0307)$ e não significativa.

No caso dos laboratórios de ciência, a realidade é um pouco diferente (figura 3). Mesmo as escolas públicas de ensino médio fluminense oferecem a facilidade a um público reduzido. As correlações são positivas, porém não significativas. Nesse caso, a não significância em ambos os níveis pode ser uma consequência do fato de municípios de dotações iguais estarem em estágios diferentes na oferta de laboratórios de ciências em escolas públicas de ensino básico. 


\section{Figura 2}

Correlações entre a razão Fundeb/PIB 2009 e a proporção de alunos dos ensinos fundamental/médio matriculados em escolas com quadra de esportes (municípios do estado do Rio de Janeiro)

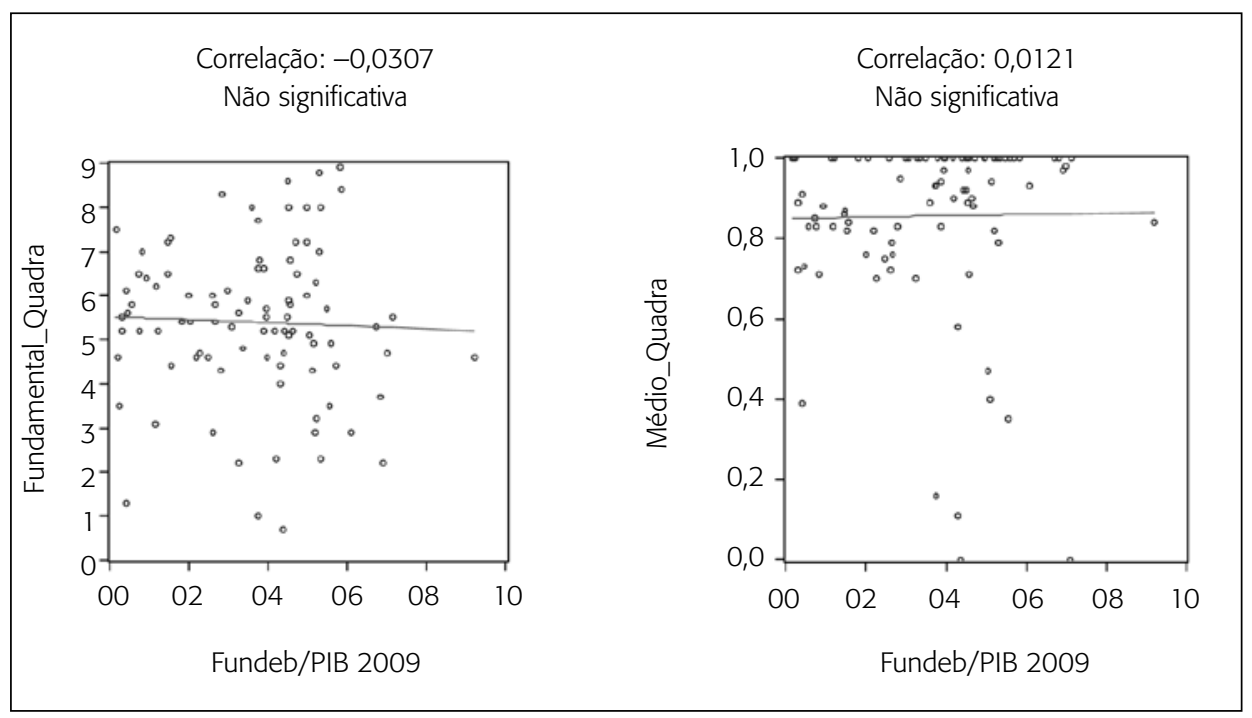

Fonte: Elaboração própria a partir de dados da Secretaria do Tesouro Nacional, Tribunal de Contas do Estado do Rio de Janeiro e MEC/Inep.

De qualquer forma, é importante chamar a atenção para a quantidade de municípios que não oferecem laboratório de ciências para alunos da rede pública em ambas as modalidades. A quantidade de pontos localizados próximos aos eixos horizontais dos gráficos denuncia essa realidade, que deveria ser diferente.

A situação de disponibilidade de microcomputadores em escolas públicas de educação básica no estado do Rio de Janeiro novamente realça o contraste entre o ensino fundamental e o ensino médio (figura 4). No caso do último, praticamente todas as escolas públicas dispõem de microcomputador, independentemente do volume de recursos que virão a receber via Fundeb. Isso explica a não significância da correlação, pois independentemente do volume de receitas a ser disponibilizado para o financiamento da educação pública, a dotação dos municípios já é razoável. No caso do ensino fundamental, a heterogeneidade novamente é a tônica. A disponibilidade de recursos do fundo não está associada aos municípios de pior desempenho. Embora a correlação seja negativa, ela não se mostrou significativa. 
Figura 3

Correlações entre a razão Fundeb/PIB 2009 e a proporção de alunos dos ensinos fundamental/médio matriculados em

escolas com laboratório de ciências

(municípios do estado do Rio de Janeiro)

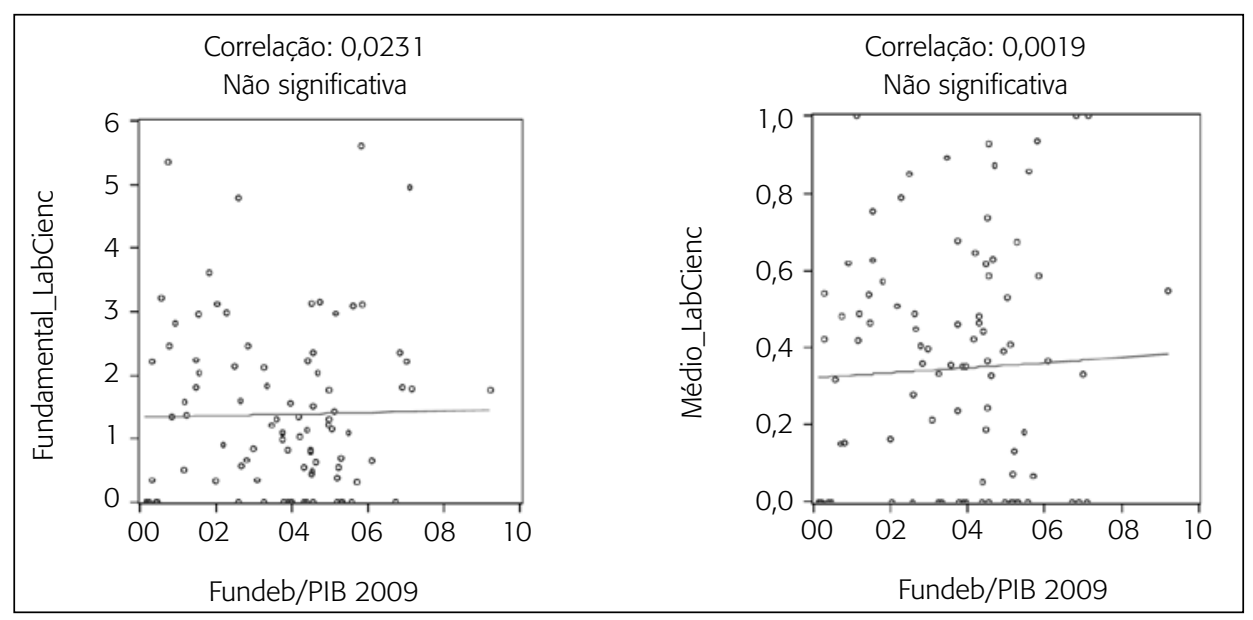

Fonte: Elaboração própria a partir de dados da Secretaria do Tesouro Nacional, Tribunal de Contas do Estado do Rio de Janeiro e MEC/Inep.

\section{Figura 4}

Correlações entre a razão Fundeb/PIB 2009 e a proporção de alunos dos ensinos fundamental/médio matriculados em escolas com microcomputador (municípios do estado do Rio de Janeiro)

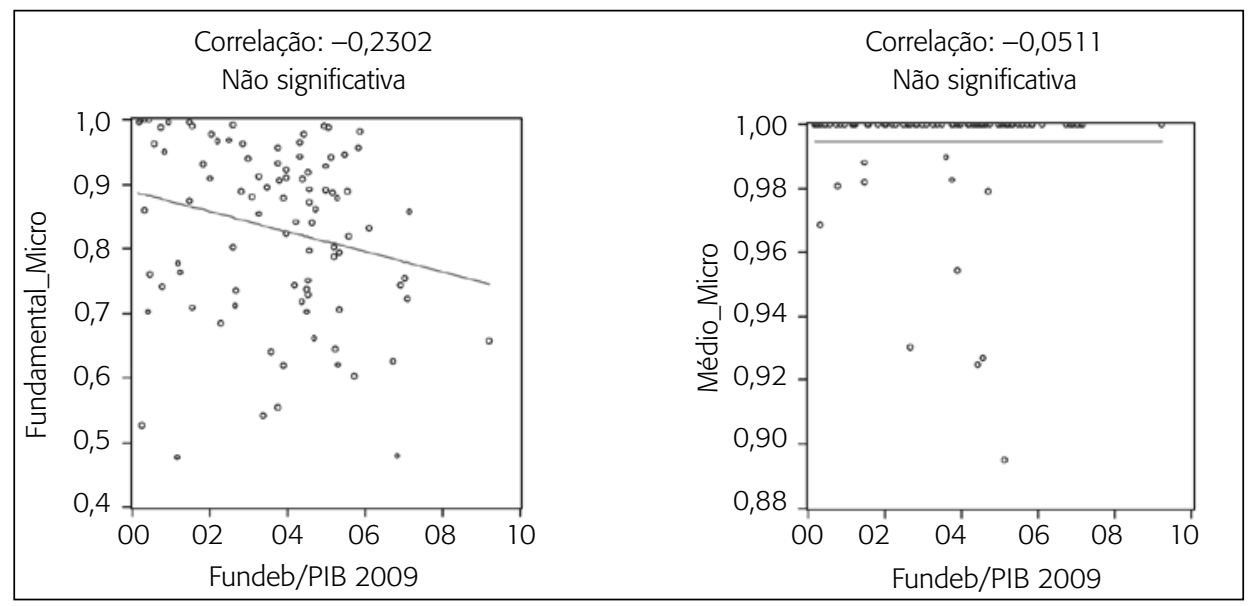

Fonte: Elaboração própria a partir de dados da Secretaria do Tesouro Nacional, Tribunal de Contas do Estado do Rio de Janeiro e MEC/Inep. 
É importante salientar a disparidade entre o ensino médio e o ensino fundamental. O primeiro apresenta uma oferta de infraestrutura complementar muito mais notável. Ainda que apresente um número bem menor de alunos, o que pode facilitar a oferta de infraestrutura, o desempenho do ensino médio tem superado o desempenho do ensino fundamental em todas as análises já apresentadas. Resta saber se, dada a expansão no número de alunos prevista para a modalidade com a implementação do Fundeb, a oferta de infraestrutura complementar para a maior parte dos alunos de ensino médio público permanecerá sendo assistida.

Além disso, é importante investigar as piores infraestruturas das escolas públicas de ensino fundamental. O fato de que a modalidade é prioritariamente oferecida pelas redes municipais (Rodrigues, 2001) faz levantar a hipótese de que as prefeituras encontram maior dificuldade de equipar suas escolas do que o governo estadual, principal provedor do ensino médio. ${ }^{5}$

A existência de microcomputador na escola não garante que, necessariamente, os alunos estejam tendo acesso à informática. A variável analisada na figura 4 mostra a disponibilidade de microcomputadores nas escolas que podem estar restritos a trabalhos internos das secretarias escolares, sem que os alunos tenham contato direto com o equipamento. Por isso, a figura 5 avalia a existência de laboratórios de informática nas escolas públicas de ensino fundamental e médio dos municípios fluminenses, confrontando-a com o peso que o Fundeb deverá representar em sua economia.

Uma primeira evidência a ser destacada é que, mesmo no ensino médio, a proporção de municípios que oferecem laboratório de informática para seus alunos de ensino básico público é menor que a proporção de alunos que estudam em escolas com microcomputador. O fato confirma a hipótese de que nem sempre os computadores existentes nas escolas estão disponíveis para os alunos.

É indiscutível a necessidade de se ampliar o acesso de alunos da rede pública de ensino básico à informática se lembrarmos que, para muitos alunos de baixa renda, essa pode ser a única oportunidade de vencer o analfabetismo digital.

A última condição de infraestrutura pesquisada é o acesso à internet. A figura 6 mostra que, a exemplo do que acontece nos casos anteriores, as escolas públicas de ensino médio parecem demonstrar um desempenho superior

\footnotetext{
${ }^{5}$ Uma discussão acerca da divisão das responsabilidades estaduais e municipais na oferta da educação básica pública pode ser lida em Sobreira e Campos (2005).
} 
às escolas de ensino fundamental. Muitos municípios possuem todos os seus alunos de ensino médio matriculados em escolas públicas com internet, independentemente da magnitude de recursos previstos a eles no Fundeb. Essa é uma explicação para a não significância da correlação negativa encontrada $(-0,0478)$.

\section{Figura 5}

Correlações entre a razão Fundeb/PIB 2009 e a proporção de alunos dos ensinos fundamental/médio matriculados em escolas com laboratório de informática (municípios do estado do Rio de Janeiro)

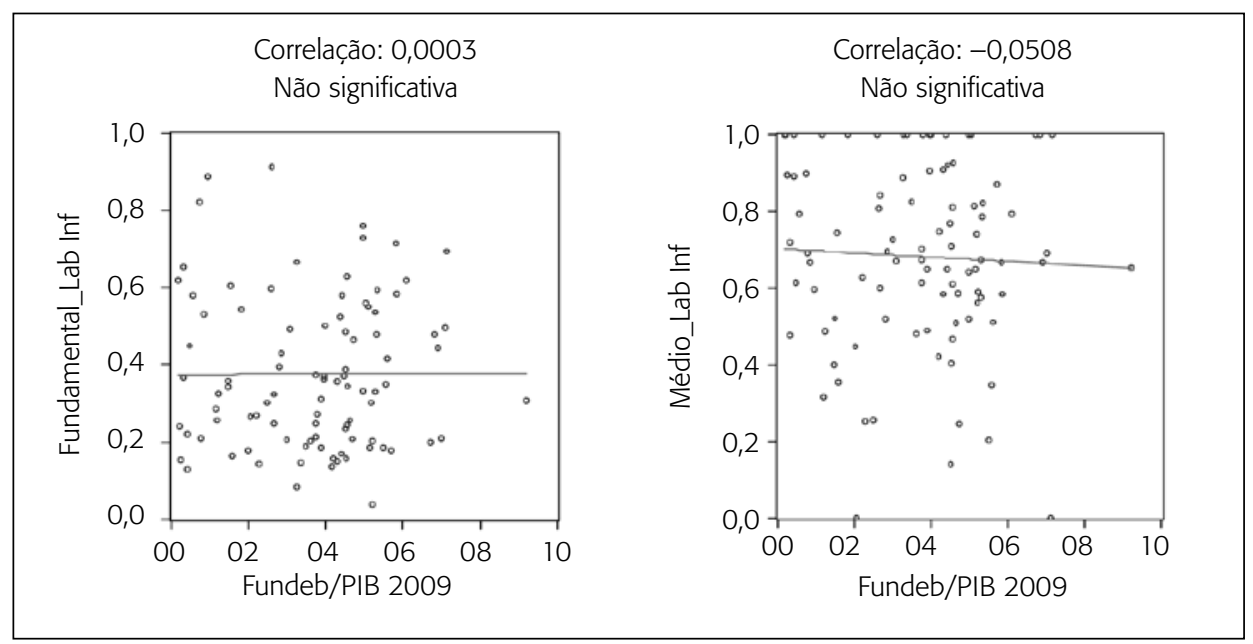

Fonte: Elaboração própria a partir de dados da Secretaria do Tesouro Nacional, Tribunal de Contas do Estado do Rio de Janeiro e MEC/Inep.

O mesmo não se pode dizer para o ensino fundamental público. A grande dispersão dos pontos no gráfico denuncia que o Fundeb não deverá privilegiar municípios que possuem poucos alunos matriculados em escolas públicas sem acesso à internet. A correlação é positiva $(0,0327)$ e não significativa, resultado, possivelmente, do fato de que municípios com dotações de recursos parecidas demonstram resultados consideravelmente diferentes.

A principal conclusão a ser extraída do exercício desenvolvido nesta seção é a inexistência de correlação estatisticamente significativa entre a disponibilidade de recursos para o financiamento da educação pública e as condições de infraestrutura dos estabelecimentos públicos de ensino básico do estado do Rio de Janeiro. Os municípios deste estado, além de se mostrarem 
heterogêneos nas questões de acesso à escola, também o são no que se refere às condições físicas de oferta do serviço.

\section{Figura 6}

\section{Correlações entre a razão Fundeb/PIB 2009 e a proporção de alunos dos ensinos fundamental/médio matriculados em escolas com internet (municípios do estado do Rio de Janeiro)}

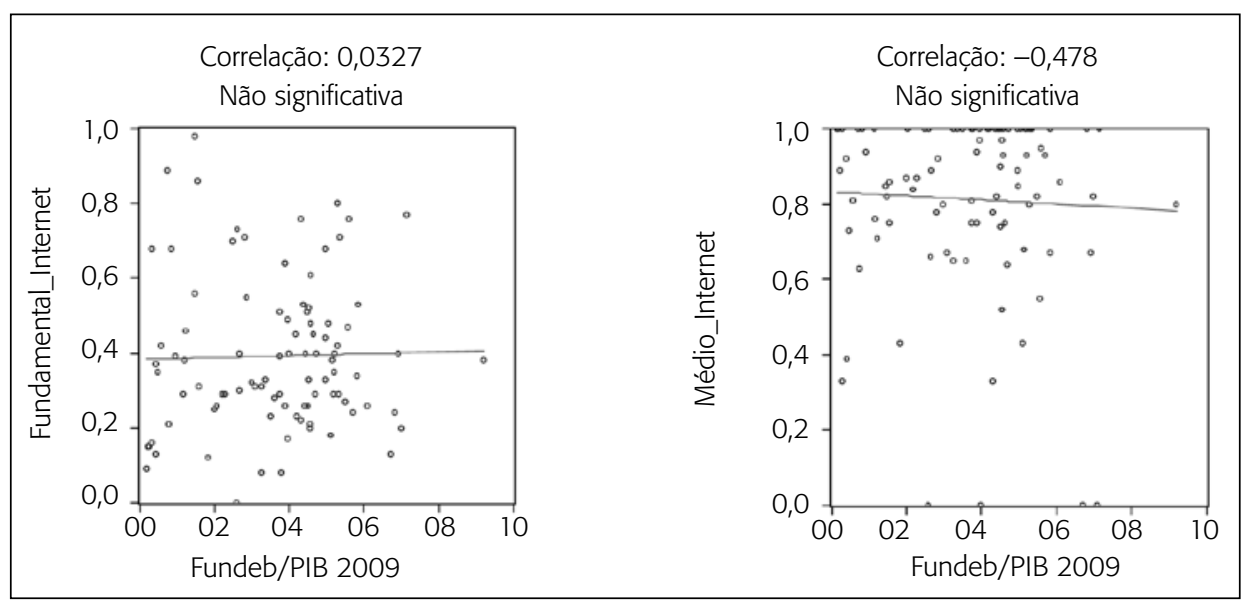

Fonte: Elaboração própria a partir de dados da Secretaria do Tesouro Nacional, Tribunal de Contas do Estado do Rio de Janeiro e MEC/Inep.

Tal evidência sugere que, ainda que seja importante do ponto de vista estrutural, o Fundeb não pode ser entendido como política capaz de promover a melhora qualitativa na educação pública brasileira. A escassez ou abundância de recursos parece não guardar relação com a qualidade da estrutura escolar, o que reforça a ideia de que a boa gestão das receitas públicas é tão importante quanto a disponibilidade das mesmas.

\section{Considerações finais}

Não é possível afirmar que o Fundeb será capaz de corrigir as disparidades qualitativas intraestaduais observadas na educação básica pública do estado do Rio de Janeiro. Aliás, sequer é possível afirmar que a disponibilidade de recursos garante uma educação de qualidade. Muito além da garantia da existência de recursos, é necessário assegurar que eles sejam bem aplicados. 
Este artigo desenvolveu uma análise que sugere que alguns municípios proporcionalmente menos dotados de recursos para serem aplicados em educação básica já apresentam uma proporção elevada de alunos matriculados em escolas com melhor infraestrutura física. Outros municípios, mesmo com maior disponibilidade relativa de recursos, não conseguem repetir esse desempenho.

Esse fenômeno também pode estar relacionado às diferenças nas quantidades de alunos em cada município. Alguns deles, com um número de alunos proporcionalmente menor, podem contar com a possibilidade de praticar gastos médios por aluno maiores. Entretanto, como a emenda constitucional do Fundeb não prevê a possibilidade de transferência de receitas de município a município, é necessário que os gestores públicos encontrem formas de melhor lidar com a escassez de recursos.

A partir das evidências apontadas nos gráficos de correlações, é possível argumentar que disponibilidade de recursos é condição necessária, porém não suficiente, para se consolidar uma educação pública de qualidade. Bom senso, vontade política e discernimento por parte dos governantes também são metas desejáveis e essenciais.

A baixa dotação de recursos computacionais e de acesso à internet nas escolas públicas brasileiras, por exemplo, poderia ser amenizada com uma melhor utilização do Fundo de Universalização dos Serviços de Telecomunicações (Fust). Criado em 2000 com o potencial de disseminar o acesso à internet nas escolas públicas brasileiras, esse fundo permanece subutilizado, o que corrobora a importância da ação política aliada à disponibilização de recursos.

O monitoramento da aplicação dos recursos por parte não só das autoridades, mas também da sociedade civil, pode ser compreendido como fator imprescindível para o êxito do Fundeb como política de reversão do atraso educacional.

\section{Referências bibliográficas}

BANCO CENTRAL DO BRASIL. Estatísticas e base de dados. 2007. Disponível em: <www.bcb.gov.br>. Acesso em: 1 mar. 2007.

BRASIL. Emenda Constitucional n. 53. Dá nova redação aos arts. 7º , 23, 30, 206, 208 e 212 da Constituição Federal e ao art. 60 do Ato das Disposições Constitucionais Transitórias. 2007a. Disponível em: <www.planalto.gov.br/ccivil_03/Constituicao/Emendas/ Emc/emc53.htm>. Acesso em: 26 abr. 2007. 
. Secretaria do Tesouro Nacional. 2007b. Disponível em: <www.receita. fazenda.gov.br>. Acesso em: 24 fev. 2007.

FUNDAÇÃO JOÃO PINHEIRO. Atlas do Desenvolvimento Humano no Brasil. 2003. Disponível em: <www.fjp.mg.gov.br>. Acesso em: 24 ago. 2006.

GREENE, J. Econometric analysis. London: Chapman and Hall, 2001.

IBGE. Sistema IBGE de recuperação automática. 2007. Disponível em: < www.sidra. ibge.gov.br>. Acesso em: 5 abr. 2007.

INEP. EdudataBrasil. 2007. Disponível em: <www.edudatabrasil.inep.gov.br> . Acesso em: 25 abr. 2007.

RODRIGUES, V. Financiamento da educação e políticas públicas: o Fundef e a política de descentralização. Cadernos Cedes, ano XXI, n. 55, nov. 2001.

SEN, A. Desenvolvimento como liberdade. São Paulo: Companhia das Letras, 2000. SOBREIRA, R.; CAMPOS, B. Disparidades regionais na educação básica brasileira: uma análise da proposta de emenda constitucional do Fundeb. In: ENCONTRO DA ASSOCIAÇÃO NACIONAL DE PÓS-GRADUAÇÃO E PESQUISA EM ADMINISTRAÇÃO — ENANPAD, 30. Anais... Salvador, BA, 2006. 